\title{
Left Posterolateral Descending Artery
}

National Cancer Institute

\section{Source}

National Cancer Institute. Left Posterolateral Descending Artery. NCI Thesaurus. Code C102314.

In an individual with a left-dominant heart, this branch arises from the circumflex artery atrioventricular groove continuation and supplies the inferior apex of the heart. 